\title{
Thick oxide MOS transistors for ionizing radiation dose measurement
}

\author{
G. SARRABAYROUSE, F. GESSINN*
}

(Manuscrit reçu le 15 avril 1994)

\begin{abstract}
The main properties of metal-oxide-silicon radiation dosemeters are described and the results obtained in terms of sensitivity and stability with thick oxide layers are given. Possible methods for improving their sensitivity are briefly discussed.

RÉSUMÉ Les principales propriétés des dosimètres de rayonnement métal-oxyde-semiconducteur (MOS) sont décrites. Nous présentons les résultats obtenus pour la sensibilité et la stabilité des dosimètres à oxyde de grille épais qui montrent que ce composant a des applications en dosimétrie des personnels et en médecine. Nous discuterons brièvement les améliorations possibles de la sensibilité.
\end{abstract}

\section{Introduction}

The first report on the use of metal-oxide-semiconductor (MOS) transistor, as integrating radiation dosemeter, was in 1970 [27]. Since then, although some groups have been working on this subject $[2,12,15,18,20,30]$, the research effort has been a small one. Various reasons are at the origin of this situation :

- there is a small market for the MOS dosemeter as an electronic component and it is of little interest in industrial and consumer electronics;

- improving its capabilities requires processing conditions counter to the general trend in modern highly integrated microelectronics which is towards low thermal budgets during processing small layer thickness ;

- as far as radiation problems are concerned, the main interest is in electronic component hardening ;

- finally, the difficulties in finding specific MOS transistors have limited the studies to low sensitivity components which are of little interest.

However, the MOS dosemeter has several advantages : small size and weight (the lateral dimensions, width and length, of the dosemeter sensitive region are not relevant parameters so that the size can be very small, in the micrometer range, and is limited only by lithography), robustness, low cost,

\footnotetext{
* Laboratoire d'analyse et d'architecture des systèmes, LAAS/CNRS, 7 avenue du Colonel Roche, F-31077 Toulouse Cedex.
} 
real-time or delayed reading, possible monolithic integration with other detectors and/or electronics, wide dose range, accuracy, possible use without power supply. These advantages have been exploited or studied only in space $[1,2,12$, 20], nuclear plants [14] military [5] or medical [9, 19] applications.

More recently work has been done to increase the sensitivity of MOS transistors $[6,8,15,21]$, thus extending the application field down to the cGy dose range. To be used for doses below $1 \mathrm{cGy}$, the dosemeters must be biased during irradiation and, in this mode, a sensitivity as high as $100 \mathrm{mV} / \mathrm{cGy}$ has been obtained [8].

Improvements can still be made both at the technology and design level [23] as will be discussed.

\section{Basic principles}

The detailed physics of MOS transistors are extensively described in the literature $[25,33]$ and here we will discuss only the main features required for understanding them.

The dosimetry of ionizing radiations using a MOS transistor is based on the measurement of the charge formed by irradiation and trapped in the gate oxide layer $\left(Q_{\mathrm{ox}} \mathrm{i}\right)$ or at the oxide-semiconductor interface $\left(Q_{\mathrm{it}}{ }^{\mathrm{i}}\right)$ (Fig. 1$)$. $Q_{\mathrm{ox}}^{\mathrm{i}}$, which is always positive, leads to a shift of the drain current $\left(I_{\mathrm{D}}\right)$-gate voltage $\left(V_{\mathrm{G}}\right)$ curve towards more negative voltages. The interface charge $Q_{i t}{ }^{i}$ also contributes to this shift and, in addition, reduces the slope of the linear part of the curve due to degradation of the carriers mobility $\mu_{\mathrm{p}}$ in the transistor channel $[3,37]$.

The threshold voltage $V_{\mathrm{T}}$, defined as the intersection of the linear part of the curve and the $V_{\mathrm{G}}$ axis, is given by:

$$
V_{\mathrm{T}}=V_{\mathrm{T}_{0}}-\frac{Q_{\mathrm{ox}}^{\mathrm{i}}+Q_{\mathrm{it}}^{\mathrm{i}}}{C_{\mathrm{ox}}}=V_{\mathrm{T}_{0}}+\Delta V_{\mathrm{T}}
$$

where $V_{\mathrm{T}}$ is the value of $V_{\mathrm{T}}$ before irradiation and $C_{\mathrm{ox}}$ is the gate capacitance.

In the case of a so-called " $P$-channel transistor" both $Q_{\text {ox }}{ }^{i}$ and $Q_{i t}{ }^{i}$ are positive and add to define $\Delta V_{\mathrm{T}}$. As a result, they are used as dosemeters and will alone be considered in the following. Furthermore, in this case, $V_{\mathrm{T}_{0}}$ and $\Delta V_{\mathrm{T}}$ are both negative so that a unipolar power supply is sufficient for reading. Also, the so-called "rebound effect" [25] is absent in $P$-channel transistors : this phenomenon is due to competitive effects of the positive charge and the negative interface states generated in $N$-channel transistors leading to a positive or negative $\Delta V_{\mathrm{T}}$ value depending on the relative values of $Q_{\mathrm{ox}}{ }^{\mathrm{i}}$ and $Q_{\mathrm{it}}{ }^{\mathrm{i}}$. 


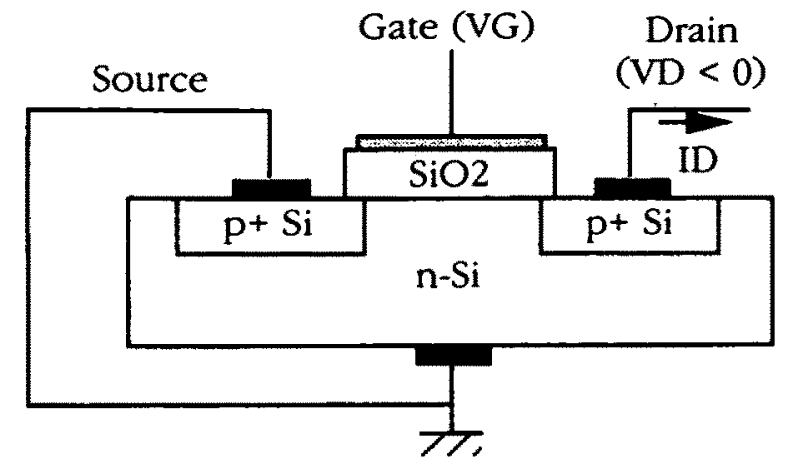

(a)

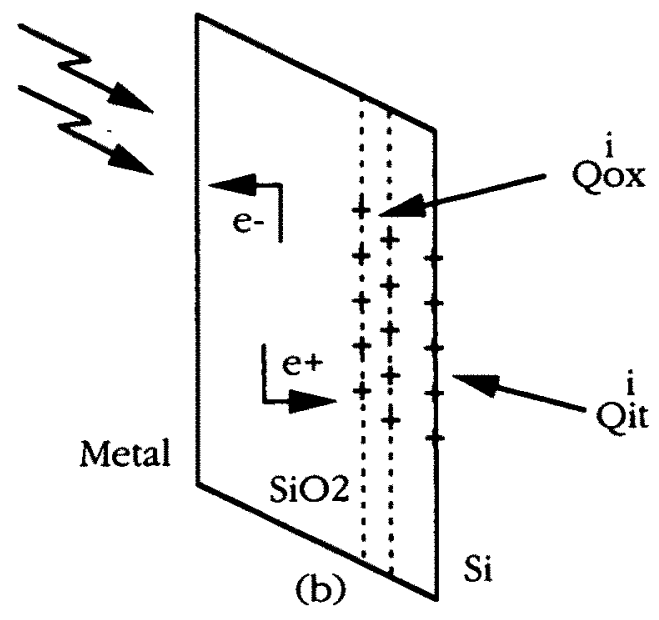

(b)

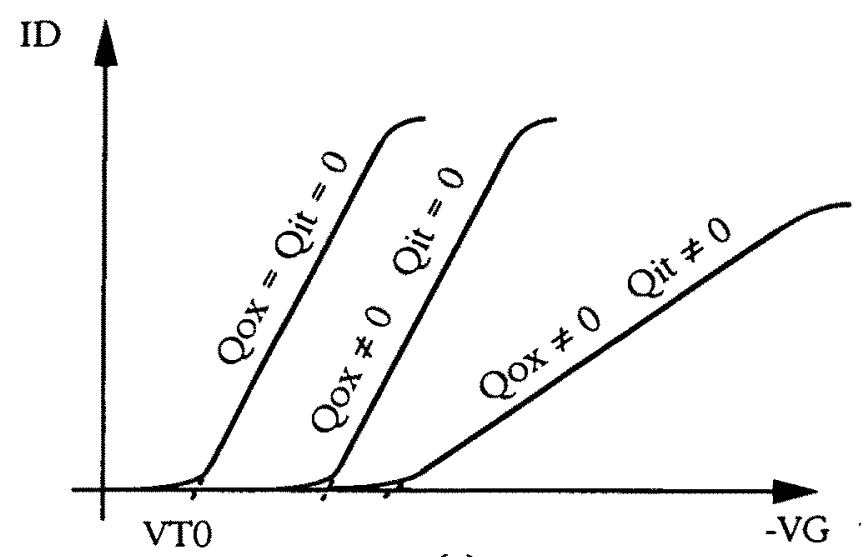

(c)

Fig. 1 - MOS dosemeter principle : (a) dosemeter schematic cross section; (b) charge and interface states formation; (c) typical transconductance curves before and after irradiation showing (graphically) the effects of the charges $Q_{o x}{ }^{i}$ and the interface states $Q_{i t}{ }^{i}$.

Principe du dosimètre MOS : (a) vue en coupe schémátique; (b) création de la charge et des état d'interface; (c) courbes typiques de la transconductance avant et après irradiation montrant schématiquement l'influence des charges $Q_{o x}{ }^{i}$ et des états d'interface $Q_{i t}{ }^{i}$.

From a practical point of view, the measured quantity is not $V_{\mathrm{T}}$ but an equivalent quantity defined as :

$$
V_{\mathrm{S}}=V_{\mathrm{T}}-\sqrt{\frac{I_{\mathrm{D}_{0}}}{\lambda}}
$$

where $I_{\mathrm{D}_{0}}$ is the current flowing through the transistor when biased by a current source as shown in Figure 2 and $\lambda$ is a constant dependent only on the channel geometry and $\mu_{\mathrm{p}}$. The measurement can be performed after or during irradiation if the dose is too low to change the hole mobility significantly, and the dose rate low enough to avoid self-biasing of the gate oxide. 


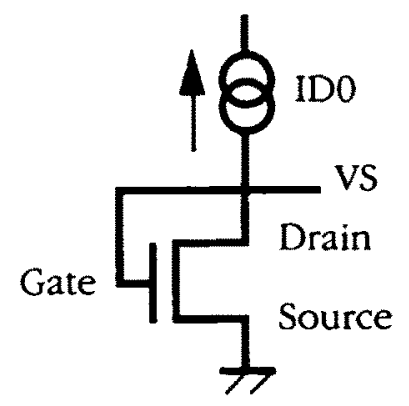

Fig. 2 - Basic measurement configuration. Configuration de base des mesures.

\section{Charges and interface states generation}

During irradiation, electron-hole pairs are formed by ionization in the oxide layer and recombine within picoseconds with a probability $f_{\mathrm{r}}$, which depends on the electric field $E_{\mathrm{ir}}$ in the oxide and the type and energy $E$ of the radiation. These pairs, which escape recombination with a probability $f_{\mathrm{nr}}=1-f_{\mathrm{r}}$ (Fig. 3) [31], are separated by the electric field. Due to their high mobility $\left(20 \mathrm{~cm}^{2} / \mathrm{V} . \mathrm{s}\right.$ at $20^{\circ} \mathrm{C}$ ) electrons are swept out of the oxide within picoseconds by the electric field and the holes move slowly towards the cathode with a mobility of about $10^{-4} \mathrm{~cm}^{2} /$ V.s $[25]$.

When the gate is positively biased during irradiation (the most favorable case for highest sensitivity), holes move towards the $\mathrm{SiO}_{2}-\mathrm{Si}$ interface and are trapped with a probability $f_{\mathrm{T}}$ at a distance $5-20 \mathrm{~nm}$ from this interface in deep traps. These have a density of about 1 to $5 \times 10^{12} \mathrm{~cm}^{-2}$, depending on the processing conditions of the oxide layer, and capture cross sections for holes, which are about 1 to $50 \times 10^{-14} \mathrm{~cm}^{2}$ depending on $E_{\mathrm{ir}}[10,36] ; f_{\mathrm{T}}$ has values between $10^{-1}$, for a hardened oxide, and 1 , for sensitive oxide layers, and appears to be a fundamental parameter in maximizing sensitivity.

Thus the trapped charge near the $\mathrm{SiO}_{2}-\mathrm{Si}$ interface can be written :

$$
\left.Q_{\mathrm{ox}}^{\mathrm{i}}=q \cdot g \cdot t_{\mathrm{ox}} \cdot f_{\mathrm{nr}} \cdot\left(E_{\mathrm{ir}}, E\right) \cdot f_{\mathrm{T}} \text { (process, } E_{\mathrm{ir}}\right) \cdot D
$$

where $g=76 \times 10^{14} \mathrm{~cm}^{-3}$. Gy -1 is the electron-hole pair generation coefficient for $\mathrm{SiO}_{2}, D$ the dose absorbed in the oxide layer, $q$ the electron charge and $t_{\mathrm{ox}}$ the oxide thickness.

These considerations apply when there is an electric field in the insulator during irradiation. However, $E_{\mathrm{ir}}$ can be reduced or even be zero if $V_{\mathrm{G}}$ is zero (unbiased dosemeter) or when the dosemeter is near saturation. In fact, when charge trapping proceeds, with the voltage across the insulator kept constant, the electric field in the generation region progressively decreases and falls to zero, thus leading to response saturation because the electron-hole pairs are no longer separated. 


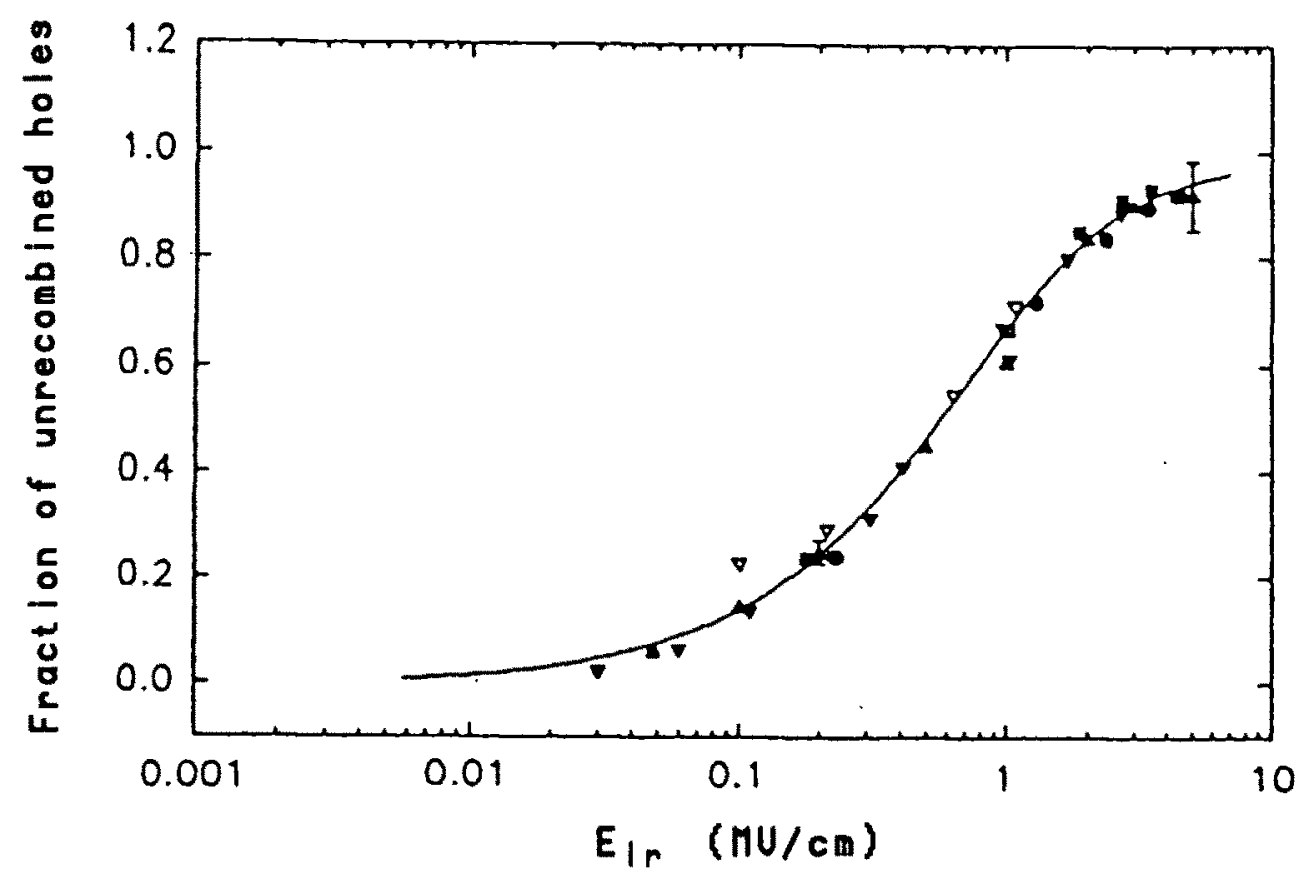

Fig. 3 - Fraction of holes which escape recombination for ${ }^{60}$ Co irradiations as a function of electric field (solid line is a fit to the data), from [31].

Fraction des trous qui échappent à la recombinaison pour les irradiations ${ }^{60} \mathrm{Co}$ en fonction du champ électrique (la ligne continue représente l'interpolation des données), d'après [31].

This model is, however, oversimplified and a detailed analysis taking carrier diffusion and space charge effects into account $[17,32]$ shows charge trapping in the absence of an applied electric field during irradiation.

Furthermore, whereas charge trapping near the electrodes in hardened or biased oxides is well established, in the case of a thick and unbiased insulator the trapping region has not been demonstrated to be near the electrodes. Such specially processed oxides could contain hole traps distributed throughout their volume.

Interface states are established during several successive periods and are easily observed after an irradiation pulse : a prompt component develops during a few milliseconds and two time-dependent delayed components grow during a few seconds and thousands of seconds, respectively. The relative extents of these periods are highly dependent on the oxide processing conditions [25].

Also, the interface states density formed during irradiation is higher when the applied bias is positive [35] but is still significant when $V_{\mathrm{Gir}}=0 \mathrm{~V}$, so that some authors consider the interface states to be at the origin of the threshold voltage shift of unbiased MOS transistors [13]. The interface states density increases with the radiation dose as a function of the electric field $E_{\mathrm{ir}}$, the processing parameters and the dose range [4, 25, 34]. 


\section{Dosemeter response}

The most important parameters which characterize the dosemeter response are sensitivity, dose linearity and time and temperature stability.

\subsection{Sensitivity}

The sensitivity is controlled by the electric field in the oxide during irradiation, as mentioned above, and by the processing conditions, which determine the hole traps density, their capture cross section and their location as well as the interface states density.

Furthermore, the oxide thickness controls the electrical response of the transistor to charge trapping as indicated in (1) and (2).

Recently published results for various processing parameters (oxidation temperature, duration and ambience, post-oxidation anneal, gate material) and for $V_{\mathrm{Gir}}=0$ are shown in Figure 4. The fact that most of the results follow the same curve indicates that the main rules for optimizing the oxidation process are now established when pure $\mathrm{SiO}_{2}$ is used as the insulator. In particular, it is clear that an oxidation temperature above $1000{ }^{\circ} \mathrm{C}$ makes it possible to obtain a significant improvement in sensitivity (" $\nabla ")$ from a non-optimized process ("+") (Fig. 4).

The second factor determining the sensitivity is $V_{\mathrm{Gir}}$. Taking into account results from Figure 2 and reliability problems with thick oxide layers (breakdown field about 6-8 MV/cm), a value of $1 \mathrm{MV} / \mathrm{cm}$ for $V_{\mathrm{ir}}$ appears to be a good

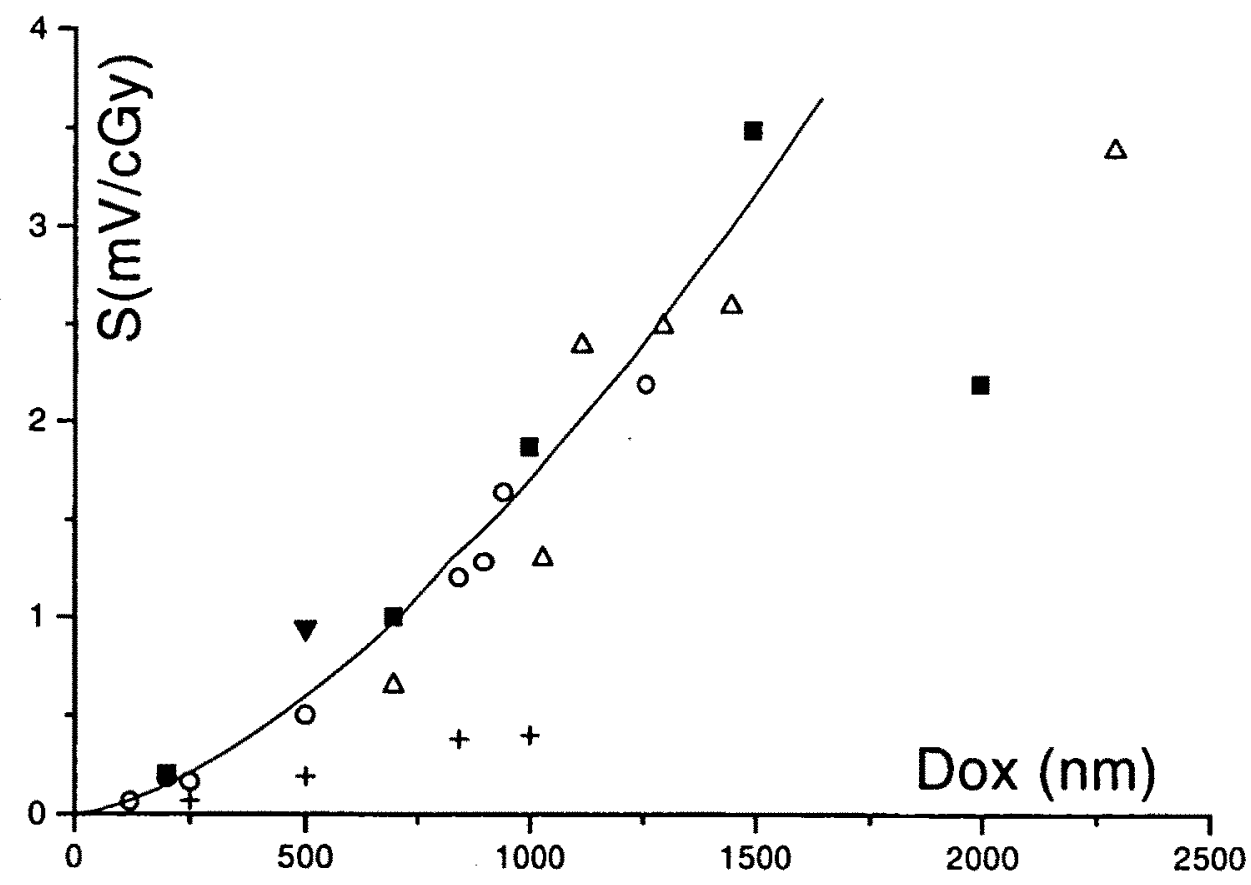

Fig. 4 - Sensivity vs oxide thickness for unbiased dosemeters.

Sensibilité en fonction de l'épaisseur d'oxyde pour des dosimètres non polarisés. 
compromise. Few results are given in the literature in this case for thick oxides due to the high values of $V_{\mathrm{Gir}}$. However, when the dosemeter does not need to be portable, these working conditions can be of interest due to the high sensitivity values which can be obtained, as shown in Figure 5 [8]. In addition, this figure shows that the sensitivity ${ }^{1}$ varies linearly with the square of the oxide thickness in agreement with (1) and (3).

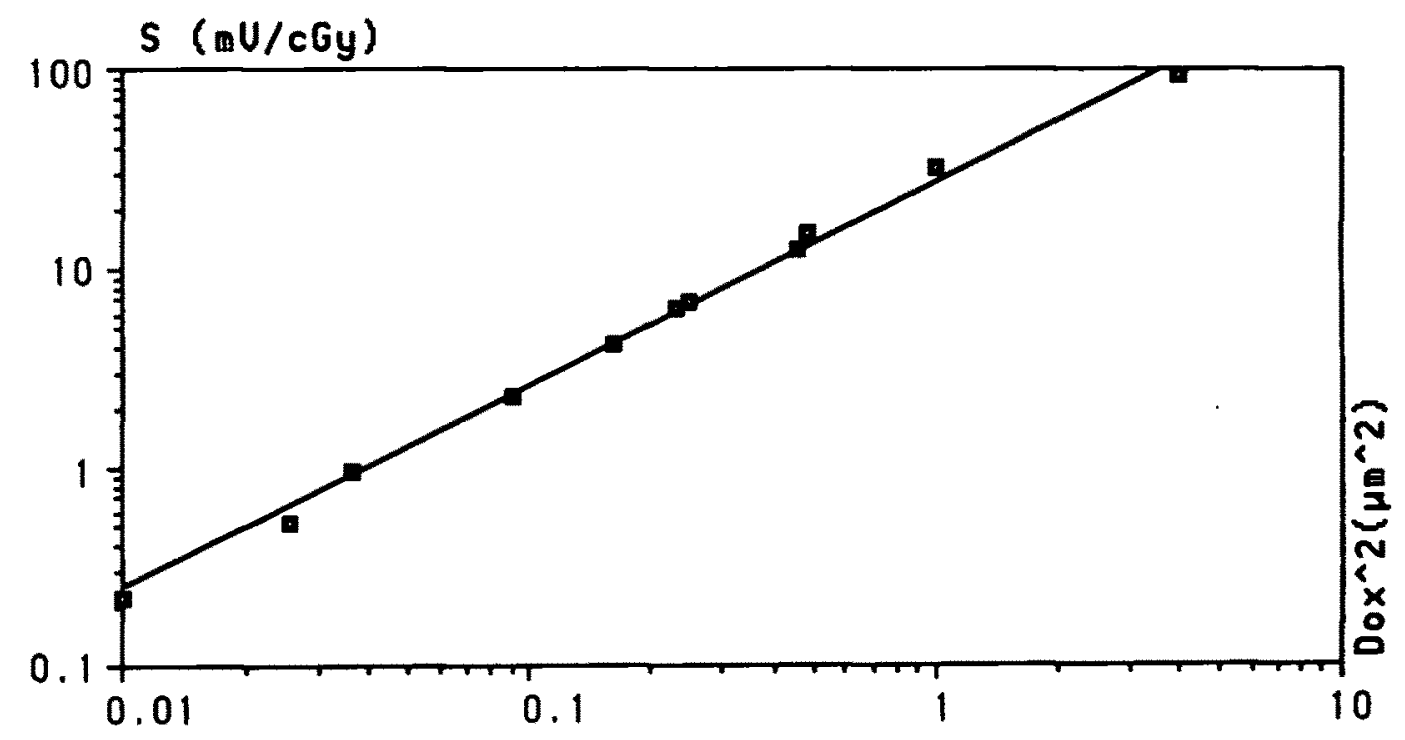

Fig. 5 - Sensitivity vs gate oxide thickness when $V_{G i r}=1 \mathrm{MV} / \mathrm{cm} . t_{o x}$ Results for $t_{o x}$ less than 1 Hm are taken from [29-30].

Sensibilité en fonction de l'épaisseur d'oxyde de grille lorsque $V_{G i r}=$ $1 \mathrm{MV} / \mathrm{cm} . \mathrm{t}_{\text {ox }}$ Les résultats pour $t_{\text {ox }}$ inférieur à $1 \mu \mathrm{m}$ proviennent de [29, 30].

Thus, by varying both the applied voltage on the gate and the insulator thickness during irradiation, the measurable dose range extends from $0.1 \mathrm{cGy}$ [8] up to at least $10^{6}$ Gy [5]. Furthermore, the possibility of integrating transistors with different oxide thicknesses in the same package offers the complete dose range with one simple dosemeter.

\subsection{Response linearity}

When a voltage $V_{\text {Gir }}$ is applied during irradiation, according to (3) the response is linear if the electric field is constant and the hole traps are not saturated (in this case, of course, $f_{\mathrm{T}}=0$ ). A typical experimental response with the applied voltage as a variable is shown in Figure 6 [29]. The response is linear at low doses and progressively saturates at a maximum value which is dependent on the applied bias. If we arbitrarily define the linear region limit by the dose where the response deviates by $5 \%$ from the linear portion of the curve then it also increases with $V_{\text {Gir }}$ (Fig. 7).

\footnotetext{
1 In this paper, all the results are for irradiations with X-rays from a CGR Aequivolt 300-150 generator unless otherwise specified.
} 


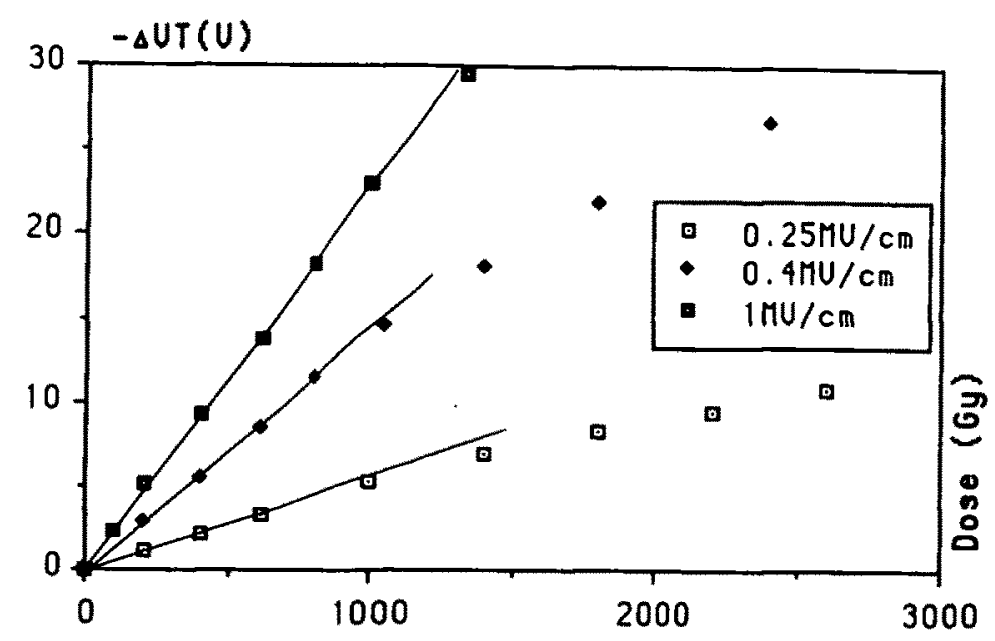

(a)

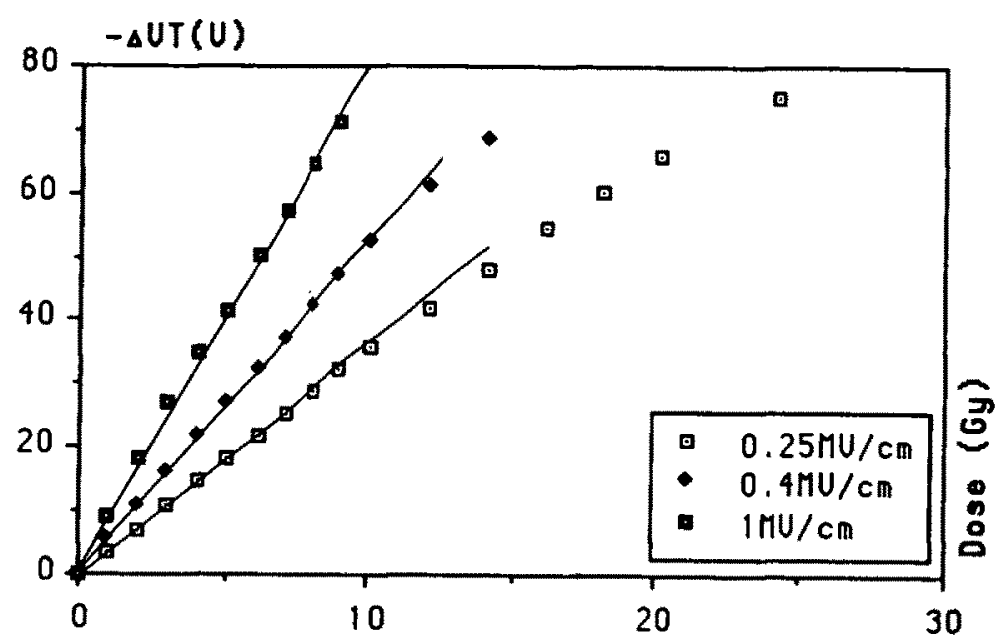

(b)

Fig. 6 - Response linearity of PMOS dosemeters with applied voltage during irradiation: (a) $t_{o x}=100 \mathrm{~nm} ;$ (b) $t_{o x}=1.5 \mu \mathrm{m}$.

Linéarité de la réponse des dosimètres PMOS avec la polarisation de grille pendant l'irradiation.

When the dosemeters are irradiated without any applied bias, there is a linear region that extends over the 0.1-10 Gy range [12] for an oxide thickness between $100 \mathrm{~nm}$ and $900 \mathrm{~nm}$. Nevertheless, the response can be easily measured over a much wider range (Fig. 8).

\subsection{Room-temperature long-term stability}

Two mechanisms that perturb the stability with time of irradiated MOS transistors have been identified [25]. They also have been observed in MOS dosemeters [15] although the associated variations were smaller than for hardened MOS transistors. The first is due to interface states which continue to be formed at the $\mathrm{SiO}_{2}-\mathrm{Si}$ interface after irradiation and produce an increase in the threshold voltage shift. This "reverse" annealing is, of course, dependent on the 


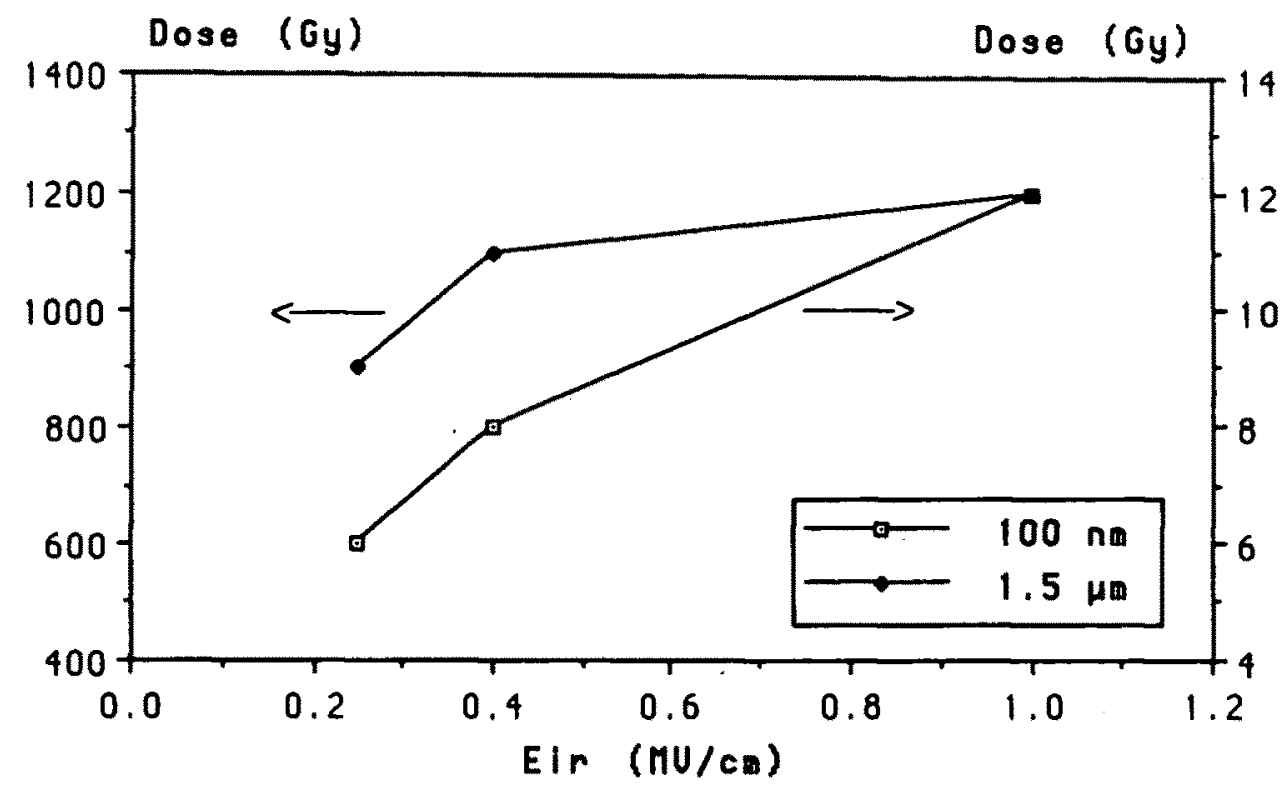

Fig. 7 - Linear region extension vs irradiation gate bias.

Extension de la région linéaire en fonction de la polarisation de grille durant l'irradiation.

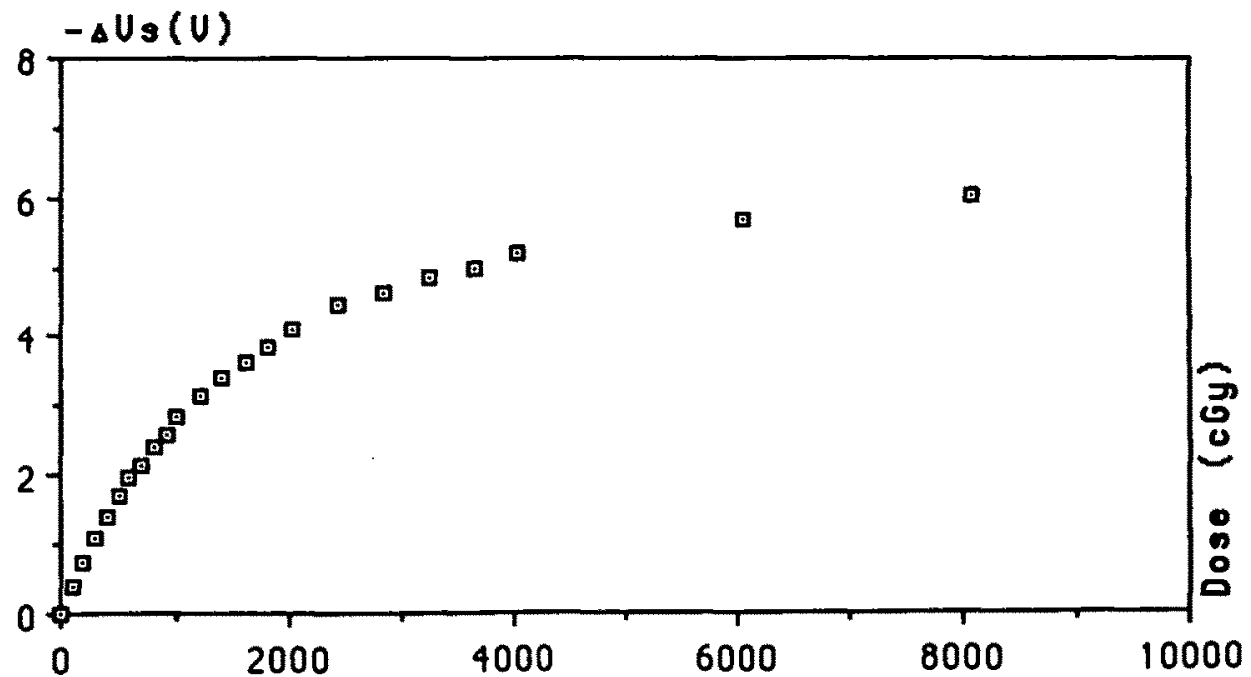

Fig. 8 - Radiation response of an unbiased dosemeter.

Réponse d'un dosimètre non polarisé au rayonnement.

applied bias after irradiation, the dose and also whether the formation of interface states is significant. With thick oxide dosemeters, we have only observed reverse annealing at a high temperature $\left(200^{\circ} \mathrm{C}\right)$. The second mechanism, which gives rise to a reduction with time of the threshold shift formed by irradiation, has been associated with the injection of electrons from the semiconductor by direct tunnelling, thus compensating for the trapped positive charges. Of course this annealing also occurs during irradiation, mainly when the irradiation is carried out with $V_{\mathrm{Gir}}>0$, and the resulting threshold shift amplitude may introduce some limitations at very low dose rates. The amplitude of the threshold shift recovery has been modelled both during and after irradiation 
[32] and the error in the dose measurement has been evaluated on the basis of the observed post-irradiation recovery. An example is given in Figure 9, which shows that the MOS dosemeter can operate correctly at very low dose rates. For a given dose $D$ and the associated acceptable error $\Delta D / D$ at this dose, the lower limit for the dose rate $B$, to ensure $\Delta D / D$, can be calculated from each curve.

In fact, experimental results $[22,28]$ show that there is a set of processing conditions which minimize the fading of PMOS dosemeters and maximize their sensitivity. In this respect, the most important parameter is the oxide layer thickness and its effect on fading is shown in Figure 10 [28]. These results are consistent with those published in [23], which show $0.3 \%$ fading at room temperature for a dosemeter with a $950 \mathrm{~nm}$ thick oxide when optimized processing conditions are applied.

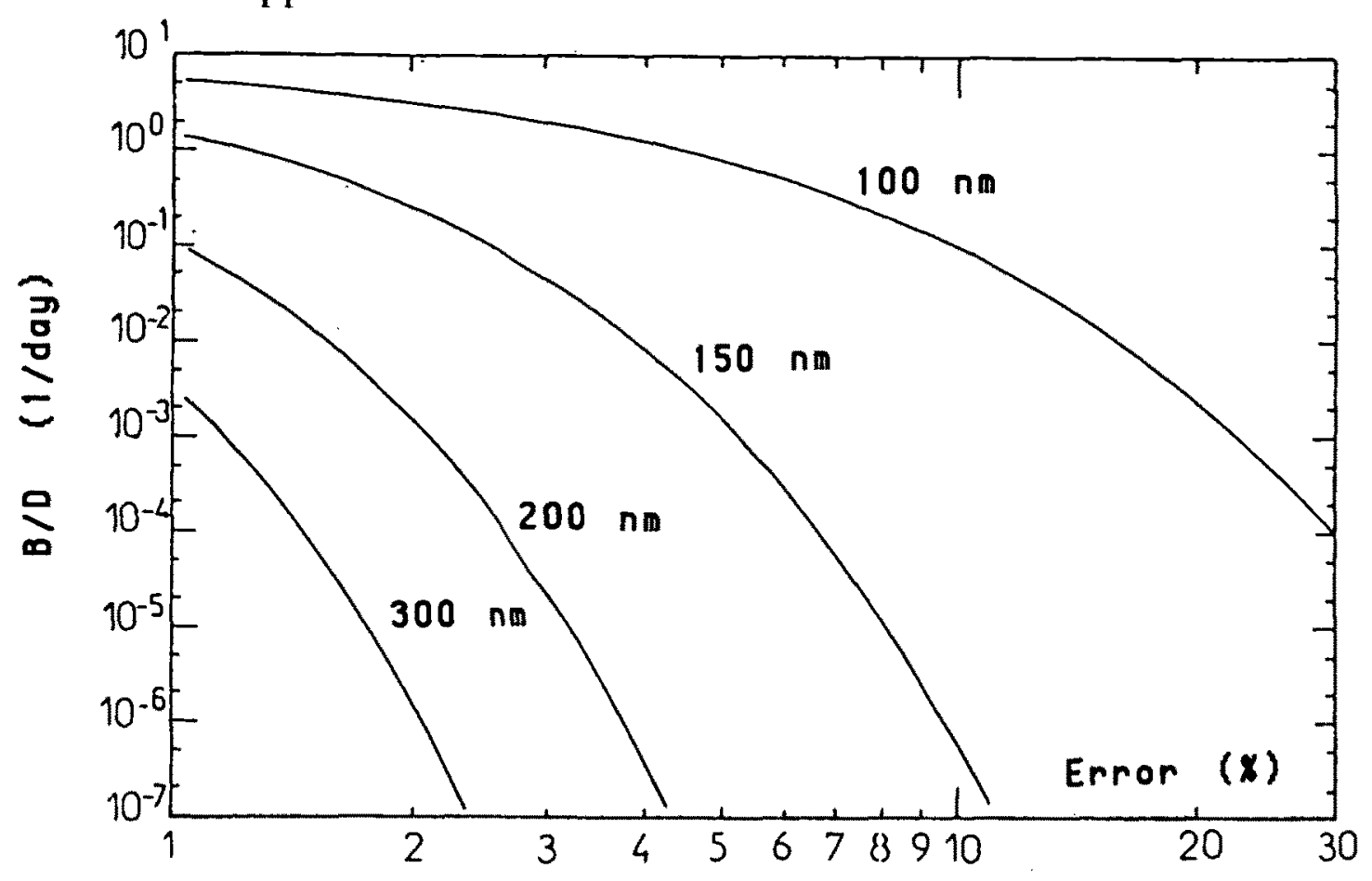

Fig. 9 - Ratio of the dose rate $B$ to dose $D$ vs the error in $\triangle D / D$ due to low values of $B$, (oxide thickness as a parameter).

Rapport $\triangle D / D$ entre le débit de dose $B$ et la dose $D$ utilisés en fonction de l'erreur commise sur la dose $D$ due aux faibles valeurs de $B$ (les courbes sont paramétrées par l'épaisseur d'oxyde).

\subsection{Read-time instability}

The threshold voltage of a biased MOS transistor may drift with time due to a rearrangement of charges formed during processing or irradiation at the $\mathrm{SiO}_{2}$-Si interface [11]. This instability, which develops immediately after turning the transistor "on" or "off", has been shown to increase with the processing conditions that maximize the sensitivity and, in particular, when the oxidethickness increases. However, its magnitude has been recently reported to be less than $0.5 \%$ of the total dose reading [23]. By tracking the dosemeter output 


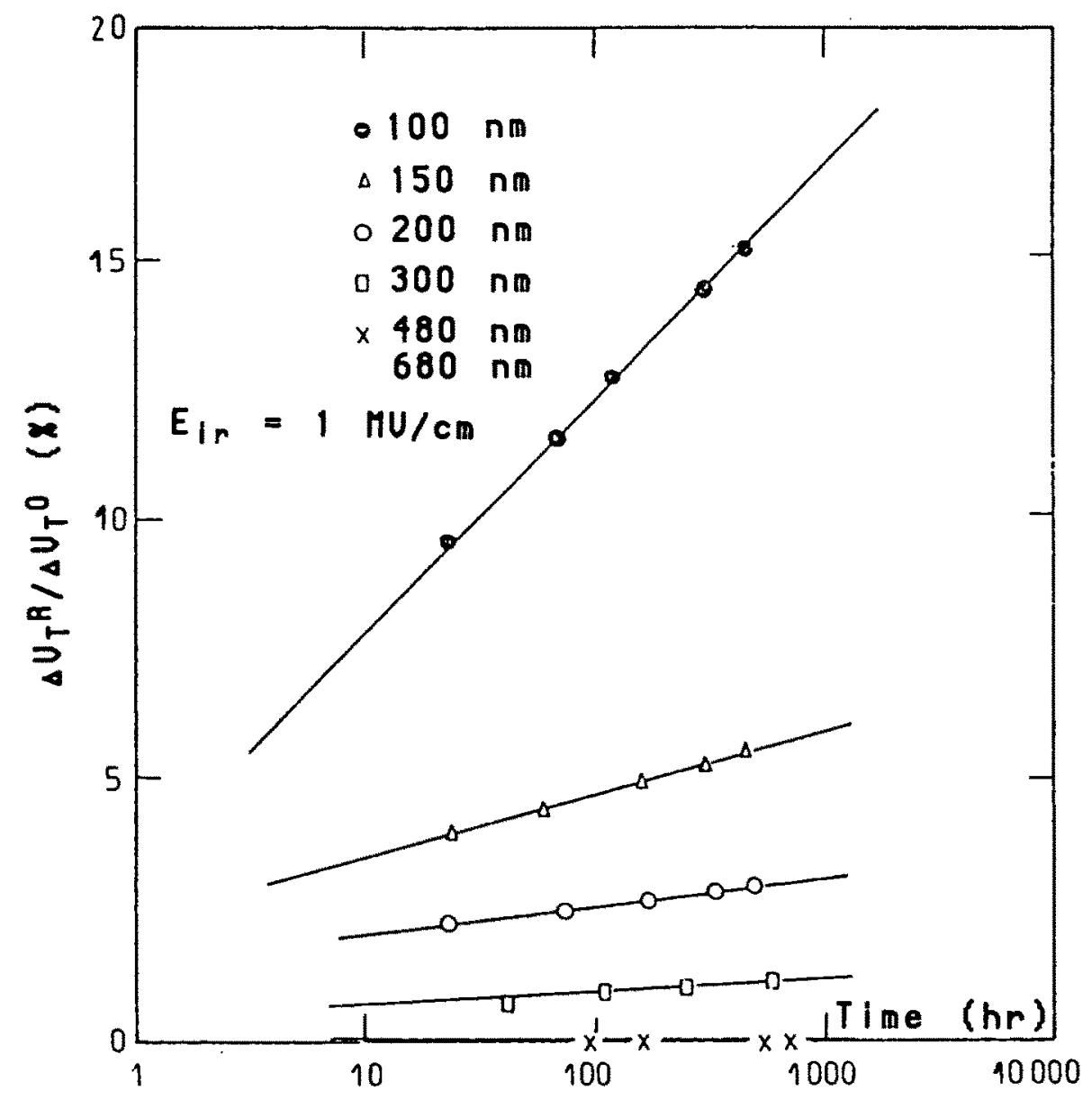

Fig. 10 - Ratio of the threshold voltage recovery $\Delta V_{T}{ }^{R}$ to the post-irradiation shift $\Delta V_{T}{ }^{0}$ vs time (oxide thickness as a parameter).

Rapport entre la récupération temporelle de la tension de seuil $\Delta V_{T}{ }^{R}$ et la dégradation initiale $\Delta V_{T}^{0}$ en fonction du temps paramétré par l'épaisseur d'oxyde.

over $30 \mathrm{~s}$, we have verified that the instability is of the order of $1-2 \mathrm{mV}$ in this time range for unirradiated dosemeters and that apparent dose increases after irradiation are always less than $1 \%$ of the total signal.

\subsection{Temperature effects}

Several factors control the temperature sensitivity of the dosemeter response to an irradiation. They include those related to the effect of temperature on the charge generation rate and those related to the reading, which are mainly associated with the threshold voltage temperature sensitivity. The latter has been shown to depend on the doping level $N_{\mathrm{D}}$ of the semiconductor and the oxide thickness [24]. Increasing both parameters leads to an increase in the $V_{\mathrm{T}}$ temperature sensitivity, which ranges from $1 \mathrm{mV} /{ }^{\circ} \mathrm{C}$, when $t_{\mathrm{ox}}=100 \mathrm{~nm}$ and $N_{\mathrm{D}}=10^{14} \mathrm{~cm}^{-3}$, to $20 \mathrm{mV} /{ }^{\circ} \mathrm{C}$ for $t_{\mathrm{ox}}=12 \mu \mathrm{m}$ and $N_{\mathrm{D}}=10^{15} \mathrm{~cm}^{-3}$. Thus, the temperature sensitivity can be a serious limitation to the dosemeter accuracy when $V_{\mathrm{T}}$ measurements are not made at a constant temperature, and, in addition, this sensitivity has been found to increase with dose [23]. 


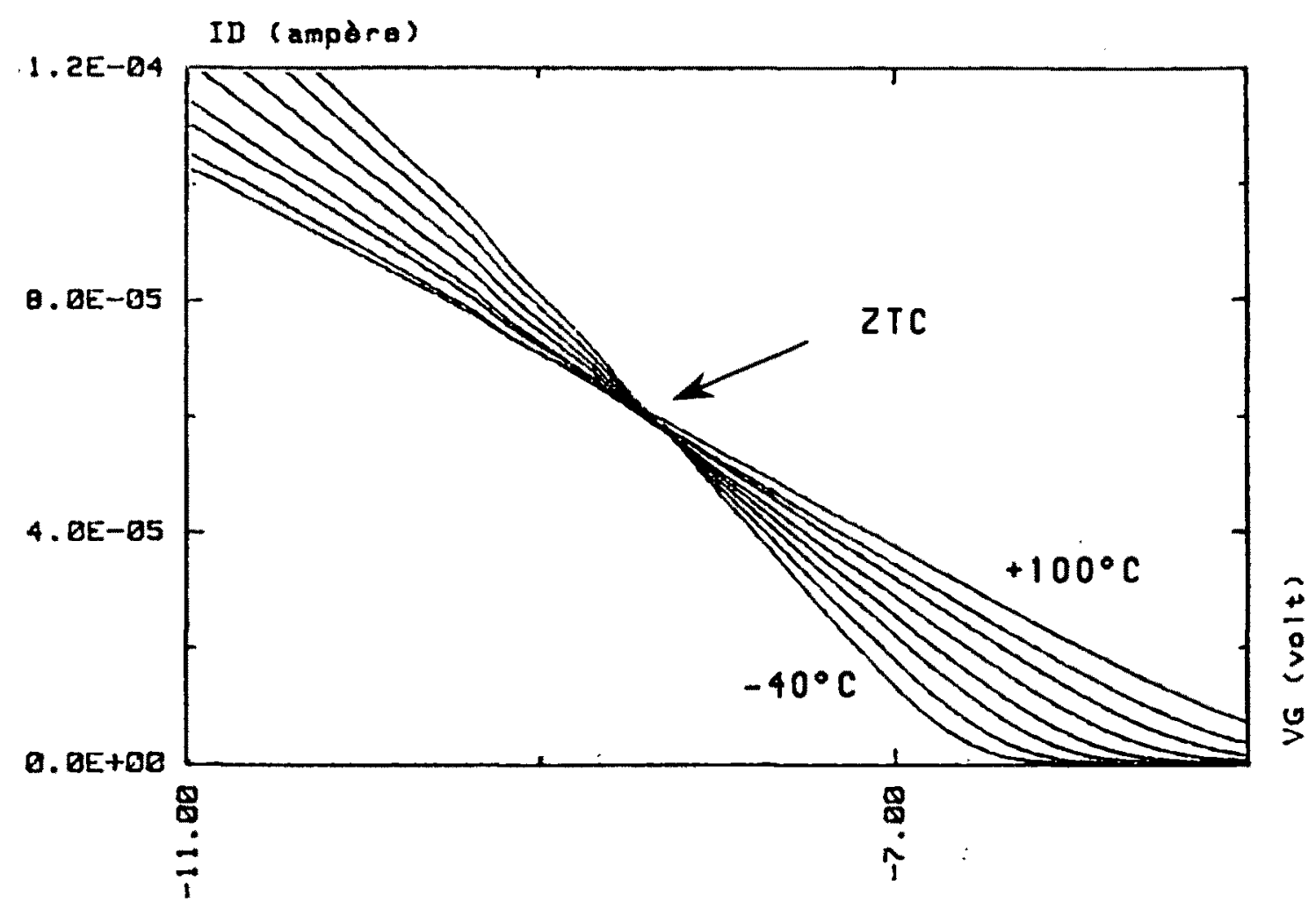

Fig. 11 - Typical drain current-gate voltage curves with temperature as a parameter (temperature step $=20^{\circ} \mathrm{C}$ ).

Courbes typiques courant de drain - tension de grille avec la température pour paramètre (le pas de température est de $20^{\circ} \mathrm{C}$ ).

One approach to the problem of the temperature-dependent threshold voltage shift is to bias the dosemeter at a point (called ZTC "zero-temperaturecoefficient") where the current remains constant when the temperature changes (Fig. 11). At this point the current is given by :

$$
I_{\mathrm{D}}(\mathrm{ZTC})=\mathrm{b} \cdot C_{\mathrm{ox}} \cdot \mu p \cdot T^{2}\left(\frac{\partial V_{\mathrm{T}}}{\partial \mathrm{T}}\right)^{2}
$$

where $\beta$ is a constant and $T$ the temperature.

Because $\mu_{\mathrm{p}}$ and $\partial V_{\mathrm{T}} / \partial T$ change on irradiation, $I_{\mathrm{D}}$ (ZTC) varies with the dose. However, this dose variation has been found to be less than $0.02 \% / c G y$ and $0.06 \% / \mathrm{cGy}$ for $t_{\mathrm{ox}}=1 \mu \mathrm{m}$ and $2 \mu \mathrm{m}$, respectively. Thus for a low dose irradiation, the variation of $I_{\mathrm{D}}$ (ZTC) with dose can be neglected. In this case, the temperature sensitivity of the dosemeter output is reduced, for example, it is $0.4 \mathrm{mV} /{ }^{\circ} \mathrm{C}$ for $t_{\mathrm{ox}}=0.5 \mu \mathrm{m}$ instead of $9 \mathrm{mV} /{ }^{\circ} \mathrm{C}$ for $\partial V_{\mathrm{T}} / \partial T$ and the same dosemeter [26].

Temperature also has an effect on the dosemeter stability. Annealing of the post-irradiation trapped charge is increased at high temperatures $[8,23]$. This has been attributed to an increase in the thermal emission of holes from the trap centers to the $\mathrm{SiO}_{2}$ valence band. However, results obtained at $200^{\circ} \mathrm{C}$ 
show that not only is the trapped charge fully annealed but also the threshold voltage can be less negative than before irradiation. This superrecovery in $P$-channel MOS dosemeters cannot be attributed to changes in the interface state density as in the case of a $N$-channel MOS transistor. It may be due to neutral centers formed by the radiation which trap electrons injected during annealing from the electrodes.

Finally, the effects of the applied gate bias during irradiation on the postirradiation stability at high temperatures have been demonstrated [23]. The positive charges trapped with $V_{\mathrm{Gir}}=0$ appeared less permanent than those trapped with a positive gate bias.

High temperature annealing is then a complicated process and no complete treatment has been developed for the case of soft oxides.

Charge annealing is a limitation in the use of the PMOS transistor at high temperatures as a dosemeter. In fact, applying the processing requirement for a minimum annealing leads to $31 \%$ recovery at $100^{\circ} \mathrm{C}$ after $280 \mathrm{~h}$ [23] and $100 \%$ recovery after $1.5 \mathrm{~h}$ at $200^{\circ} \mathrm{C}$ [8].

\section{Possible improvement of the dosemeter response}

The sensitivity can be improved first by designing the dosemeter to incorporate a stack of MOSFETs (Fig. 12) [23]. Here, if $n$ transistors are stacked, the sensitivity is about $n$ times that of a single transistor. It has been shown that a limit to $n$ is introduced by the fact that the output voltage cannot exceed the drain/bulk breakdown voltage. Therefore, to increase the $n$ value and thus increase the sensitivity or to extend the accessible dose range, the individual threshold voltage must be as low as possible. This can be achieved using an ion-implantation threshold adjustment of each transistor.

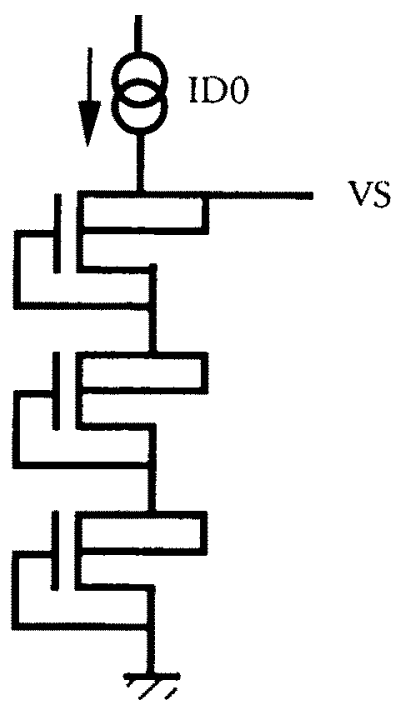

From a technological viewpoint, an improvement could be obtained from an additional oxide thickness increase. Combining both thermal oxidation and chemical vapor deposition, a thickness of several micrometers can be obtained with good quality for the $\mathrm{SiO}_{2}$-Si interface. This was done in [7] up to $2.3 \mu \mathrm{m}$ but the sensitivity did not follow the general trend shown in Figure 4, possibly due to electron trapping at the thermally-deposited $\mathrm{SiO}_{2}$ interface as suggested by the authors.

Fig. 12 - Measurement set-up with three dosemeters stacked, each bulk connection is tied to the source of the individual transistors.

Montage expériemental de mesure avec trois dosimètres en cascade (chaque connexion de substrat est reliée à la source du même composant). 
A second way to improve the sensitivity is to increase the trapping sites density. This can be done by implanting impurities in the oxide layer $[6,17]$. It has been shown, for example [16], that an arsenic implantation, followed by suitable annealing, generates hole traps in the insulator. An improvement factor of better than 10 has been obtained in this way using a $70 \mathrm{~nm}$ thick oxide.

\section{Conclusions}

The applicability of MOS ionizing radiation dosemeters, some of which are commercially available, to various fields has been demonstrated. Most of their properties are unique compared to other dosemeters. The dynamic range is very wide, from $1 \mathrm{mGy}$ to $10^{5}$ Gy with an accuracy which, depending on the measurement conditions and the dose range, can be within a few percent. The main limitation comes from temperature variations which may introduce appreciable errors when the dosemeter is used unbiased. This mode is attractive for applications in personnel dosimetry and medicine. The highest sensitivity achieved to date is about 3-4 $\mathrm{mV} / \mathrm{cGy}$ with a read-time instability of about $1 \mathrm{mV}$. Thus at present, assuming a constant temperature, 2-5 cGy can be measured with an accuracy within $10 \%$ (ou with an uncertainty of less than $10 \%$ ). It should be noted that as $5-10 \mathrm{~V}$ batteries are available with small size and weight, irradiations with such a voltage is possible, thus improving the sensitivity and extending the dose range.

With respect to possible improvements, it appears that the limits of the basic metal pure thermal $\mathrm{SiO}_{2}-\mathrm{Si}$ technology have been reached. Nevertheless, an increase in sensitivity of about 2 to 3 can be obtained by stacking transistors. Furthermore, an additional improvement, difficult to evaluate quantitatively, will certainly be obtained in the future by using ion-implanted oxide layers.

\section{Acknowledgements}

It is a pleasure to acknowledge the skilful assistance of $F$. Rossel and T. Do Conto in the dosemeter processing and that of $N$. Kumurdjian in the electrical measurements.

\section{REFERENCES}

[1] ADAMS L., HOLMES-SIEDLE A.G. - The development of a MOS dosimetry unit for use in space. IEEE Trans. Nucl. Sci., 1978, NS-25(6), 1607-1612.

[2] AUGUST L. - Design criteria for a high dose MOS dosimeter for use in space. IEEE Trans. Nucl. Sci., 1984, NS-31(1), 801-803.

[3] BELLAOUAR A., SARRABAYROUSE G., ROSSEL P. - Influence of ionizing radiation on the channel mobilities of MOS transistors. IEE Proc., 1985, 132 (part I) 184-186.

[4] BOESCH H.E., TAYLOR T.L. - Charge and interface state generation in field oxides. IEEE Trans. Nucl. Sci., 1984, NS-31(6), 1273-1279. 
[5] BRUCKER G.J., KRONENBERG S., JORDAN T. - Tactical army dosimeter on PMOS single and dual gate insulators. In : RADECS 93, Saint-Malo (France), Sept. 13-16, 1993. (LERAY J.L., Ed.). Piscataway : IEEE, 1994, 56-62.

[6] DAWES W.R., SCHWANK J.R. - An IC compatible ionizing radiation detector. IEEE Trans. Nucl. Sci., 1981, NS-28(6), 4152-4155.

[7] ENSELL G., HOLMES-SIEDLE A., ADAMS L. - Thick oxide pMOSFET dosimeters for high energy radiation. Nucl. Inst. Meth. Phys., 1988, $A(269)$, 655-658.

[8] GESSINN F., SARRABAYROUSE G. - MOS transistors with $>1 \mu \mathrm{m}$ thick gate oxide for ionizing radiation dosimetry. In : Mater. Res. Soc. Symp. Proc., 1993, 302, 555-560.

[9] GLADSTONE D.J., CHIN L.M. - Automated data collection and analysis system for MOSFET radiation detectors. Med. Phys., 1991, 18(3), 542-548.

[10] HEYNS M., SCHWERIN A.V., KELLEHER A., KUBOTA M., VERHAVERBEKE S. In : The physics and chemistry of $\mathrm{SiO}_{2}$ and the $\mathrm{Si}_{-} \mathrm{SiO}_{2}$ interface (C.R. Helms, B.E. Deal Eds.) New York : Plenum Press, 1993, 411-420.

[11] HOLMES-SIEDLE A.G., ADAMS L. - The mechanisms of small instabilities in irradiated MOS transistors. IEEE Trans. Nucl. Sci., 1983, NS-30(6), 4135-4140.

[12] HOLMES-SIEDLE A.G., ADAMS L., MARSDEN S., PAULY P. - Calibrating and flight testing of a low-field PMOS dosimeter. IEEE Trans. Nucl. Sci., 1985, NS-32(6), 4425-4429.

[13] HOLMES-SIEDLE A.G., ADAMS L. - RADFET : a review of the use of metal-oxide-silicon devices as integrating dosemeters. Radiat. Phys. Chem., 1986, 28(2), 235-244.

[14] HOLMES-SIEDLE A.G., ADAMS L., LEFFLER S., LINDGREN S.R. - The RADFET system for real-time dosimetry in nuclear facilities. In : $7^{\text {th }}$ Annual ASTM Euratom symposium on Reactor dosimetry, Strasbourg (France), Aug. 27-31, 1990.

[15] HOLMES-SIEDLE A.G., ADAMS L., ENSELL G. - MOS dosimeters - improvement of responsivity. In : RADECS 91, Montpellier (France), Sept. 9-12, 1991 (Charles J.P., Adams L., Holmes-Siedle, Eds.). Piscataway : IEEE, 1992, 65-69.

[16] HUGHES R.C., EERNISSE E.P., STEIN H.J. - Hole transport in MOS oxides. IEEE Trans. Nucl. Sci., 1975, NS-22, 2227-2233.

[17] HUGHES R.C. - Theory of response of radiation sensing field effect transistors. J. Appl. Phys., 1985, 58(3), 1375-1379.

[18] HUGHES R.C. - Theory of response of radiation sensing field-effect transistors in zero-bias operation. J. Appl. Phys., 1986, 60(3), 1216-1217.

[19] HUGHES R.C., HUFFMAN D., SNELLING J.V., ZIPPERIAN T.E., RICCO A.G., KELSEY C.E. - Miniature radiation dosimeter for in-vivo radiation measurements. Int. J. Radiat. Oncol. Biol. Phys., 1988, 14(5), 963-967.

[20] KAY K., MÜLLEN E., STAPOR W., CIRCLE R., McDONALD P. - CRRES dosimetry results and comparisons using the space radiation dosemeter and p-channel MOS dosemeters. IEEE Trans. Nucl. Sci., 1992, NS-39(6), 1846-1850.

[21] KELLEHER A., O'SULLIVAN M., RYAN J., O'NEILL B. LANE W. - Development of the radiation sensitivity of PMOS dosemeters. IEEE Trans. Nucl. Sci., 1992, NS-39(3), 342-346.

[22] KELLEHER A., McDONNEL N., O'NEILL B., LANE W., ADAMS L. - Investigation of long-term fading in PMOS dosemeters. In $: 2^{\text {nd }}$ ESA Conference on Electronic components, ESTEC, Noordwijk, Netherlands, May 24-28, 1993.

[23] KELLEHER A. - IC dosimeter development, Ph.D. thesis, The National University of Ireland, NMRC Cork, May 1993.

[24] KLAASEN F.M., HES W. - On the temperature coefficient of the MOSFET threshold voltage. Solid-State Electron., 1986, 29(8), 787-789.

[25] MA T.P., DRESSENDORFER P.V. - Ionizing radiation effects in M.O.S. devices and circuits. New York : J. Wiley \& Sons, 1989. 
[26] O'SUllivaN M., KELLEHER A., RYAN J., O'NEILL B., LANE B. - Temperature compensation of PMOS dosimeters. In : ESA Conference on Electronic components, ESTEC, Noordwijk, Netherlands, November 12-16, 1990.

[27] POCH W., HOLMES-SIEDLE A.G. - RCA Engineer, 1970, 16(3), 56.

[28] SARRABAYROUSE G., BELLAOUAR A., ROSSEL P. - Dérive temporelle post-irradiation dans les dosimètres MOS. Rev. Phys. Appl., 1986, 21, 131-137.

[29] SARRABAYROUSE G., BELLAOUAR A., ROSSEL P. - Electrical properties of MOS radiation dosemeters. Rev. Phys. Appl.,1986, 21, 283-287.

[30] SARRABAYROUSE G. - MOS radiation dosemeter : sensitivity and stability. In : RADECS 91, Montpellier (France), Sept. 9-12, 1991 (Charles J.P., Adams L., Holmes-Siedle, Eds.). Piscataway : IEEE, 1992, 57-59.

[31] SHANEYFELT M.R., FLEETWOOD D.M., SCHWANK J.R., HUGHES K.L. - Charge yield for cobalt-60 and $10 \mathrm{keV} X$-ray irradiations of MOS devices. IEEE Trans. Nucl. Sci., 1991, NS-38(6), 1187-1194.

[32] SOCKEL R., HUGHES R.C. - Numerical analysis of transient photoconductivity in insulators. J. Appl. Phys., 1982, 53(11), 7414-7424.

[33] SZE S.M. - Physics of semiconductors devices. New York : J. Wiley, 1981.

[34] WINOKUR P.S., BOESCH H.E. - Interface-state generation in radiation-hard oxides. IEEE Trans. Nucl. Sci., 1980, NS-27(6), 1647-1650.

[35] WINOKUR P.S., ERRETTE B., FLEETWOOD D.M., PERRY J., DRESSENDORFER P.V., TURPIN D.C. - Optimizing and controlling the radiation hardness of a Si-gate CMOS process. IEEE Trans. Nucl. Sci., 1985, NS-32(6), 3954-3960.

[36] TZOU J.J., SUN J.Y., SAH C.T. - Field dependence of two large hole capture cross sections in thermal oxide on silicon. Appl. Phys. Lett., 1983, 43, 861-863.

[37] ZUPAC D., GALLOWAY K.F., SCHRIMPF R.D., AUGIER P. - Effects of radiation-induced oxide-trapped charge on inversion-layer hole mobility at 300 and $77 \mathrm{~K}$. Appl. Phys. Lett., 1992, 60(25), 3156-3158. 